\title{
DETERMINISTIC ILLUSION IN THE ORGANIZATIONAL SCIENCES: SERVICE OR SABOTAGE?*
}

\author{
L. Delf Dodge \\ The University of Michigan
}

In the course of a recently completed research project designed to test an expectancy model of work effort longitudinally, I, quite by chance, wandered through a looking glass. One quiet evening, curled up with a book and blanket in my favorite chair, warmed by thoughts of the project's remarkable success, my attentions turned. How would it have felt to be one of my own subjects in the project? How would I have reacted to demands to complete a series of questionnaires requesting information about the importance of outcomes I expected to accrue from taking a course, the time and effort I spent in preparing for an exam, the likelihood of desired outcomes actually occurring, felt equity in outcome distribution, and the like? What would I have learned had I been on this other side?

As an instructor, I might have hoped that filling out all the questionnaires would give students an appreciation of the research process. The battery of instruments was, I believe, a reasonably good one, and the data have been delightfully fruitful (at least for me). But did anything actually come of the experience for students? With what were they left? What did they learn from this exposure to research? How did they feel about the process? In fact, what did they even know of it?

Tinged with guilt at the thought of being so troublesome to the very people I was trying to help, I considered the potential. If only students could see research as the practical tool it is. Were they familiar with basic research techniques, such tools could be used to discover, order and predict behavior within their own organizational setting. Furthermore, stu-

${ }^{*}$ Thanks are due to Sam Jelinek for her helpful commentary on earlier drafts of this manuscript. dents might find that methods of collecting data and analyzing results less formal, than those used by those of us who conduct research for a living, might help them develop their own theories of human and organizational behavior to apply in their jobs. In other words, could I translate our scientific inquiry into a practical, applicable form for managers so they could realize how useful research tools might be as they progress through their careers?

I doubt that much of this type of learning occurred. Most students did not appear the slightest bit interested in the specifics of what they were going through. Instead, the steps were dutifully followed. For many, if not most, the summary experience of participating in this study was likely negative. I probably irritated some by swamping their lives with "useless" measures, and annoyed others as they felt the exam material crammed in the night before slip out of shortterm memory as they tried to answer a question about how important it was that they experienced a sense of achievement from taking the examination.

I then thought about the related issue of what was the value of the research-based theories I had presented in class. Did these rays of knowledge that I had so diligently attempted to shed demonstrate the practical usefulness of the course's content? Thinking back to students' responses in class, passive rejection or active challenge to the application and usefulness of the research seemed more the case. Memorizing of existing research and theory for use on exams presented only the illusion of learning. Such "learning," however, existed in isolation, safely separated from students' own personal theories of individual and organizational behavior. 
What was the problem? Was it the students (who I could accuse of seeking only "instant answers," and not wanting to think)? Or was it us and the field? Are we afraid to admit the immaturity of our discipline and the tentativeness of our conclusions? Are we disguising our sheepish probabilistic theories in the wolf's skin of deterministic statements? If we do this to increase our credibility, what will the consequences be when we prescribe unproven theories as cures to ailing organizations? What is wrong with being probabilistic and making a full disclosure of the position? Would our theories and research be more useful to our students if we did?

The organizational sciences have produced very little in the way of conclusive support for their theories. We may contest on the basis of complexity, "newness" of the fields or inadequate measures, but the judgment remains. We must plead guilty to having accumulated few certainties about the causes, consequences or constructs involved in organizational and behavioral phenomena. We can only predict on probabilistic bases. We have no certainties. However, just because the relationships among theoretical variables under study have not been proven (rendered deterministic) does not mean they should be deleted from a course outline, or not applied in an operating work setting. But, the state of a theory's development should be honestly reflected. How is the theory supposed to work? How has it worked in the past? What are the dangers involved in the process of applying it? Are there any potential dysfunctional outcomes? How should such negative outcomes be dealt with?

Students know that our knowledge is not definitive. They do not enter our classes ignorant of the field (which may be the case when they take finance or accounting). Instead, students' theories of human behavior are well established. They may not know exactly what their theories are, or how to describe them in words, but they do know they've been working the fields for several years and getting good yields from the theories that have grown in them. (Indeed, if their theories of behavior hadn't worked, students might be more receptive to ours.)

We, as professors, are challenged to replace the theories under which students are operating with those we convey in class. It's like trying to convince a farmer who's grown tobacco for twenty-five years and is ready to harvest another bumper crop in a few weeks, that he ought to pull the plants up and put soybeans in instead. It takes a very convincing argument to even get the farmer to admit the idea is a reasonable one, let alone follow through with it. Professors are thus forced to defend organizational science theories not only on an absolute basis of accuracy and usefulness, but also on a comparative basis; to prove what we have to offer is better than the system students have developed for themselves. Other disciplines are not faced with the problems of teaching entire classes of experts in the field. Our credibility comes under attack. How do we know we're better? How do they know we're better?

Even though students may know that the organizational sciences are not deterministic, they are likely to judge its value in terms of the definitiveness of the answers that can be given. Again, our field suffers in comparison with others. When students read accounting or decision science books, there appear to be definite answers to the questions. When they take exams, they use calculators which present "precise" answers. Look at the display panel. See those numbers? That's the answer. But in the organizational sciences, if we are truly honest, we have to say "it depends" more often than we can say "we know." How can we help students come to see the value of probabilistic thinking?

\section{Abandoning Illusion: A Viable Solution}

In contemplating the difficult choices before the field, it occurred to me that the dilemma might be resolved through an adjustment in pedagogical technique. If students could be taught the process of coming to "know" on their own, professors wouldn't be under a moral obligation to instruct them in only those theories which had accumulated empirical support. If students were sufficiently familiar with research processes, they ought to be capable of judging a theory's usefulness and accuracy. It sounded worth trying.

The challenge was this: to translate scientific inquiry into a practical, applicable form. Teaching MBA students to conduct research the way we do wouldn't be right. They don't want to be like us. They want to be managers; practitioners; respected; well-paid. If only I could (1) dispell the damaging illusion that determinism is a prerequisite of value, (2) give students an idea of how to go about developing new theories and testing old ones, (3) offer them the skills to do it, and (4) indicate how useful good theories can be in helping them manage in their own work settings. But how?

Here's what I came up with (parts of the model have been tested on MBA students and work amazingly well).

1. In the first session of the course I sketch a contrast between the relative determinism of students' other courses (e.g., accounting, management science), and the probabilistic nature of organizational sciences. The field is described as dealing with human equations, in which masked variables of unknown, changing importance affect behavior. Sciences devoted to 
the study of human and organizational natures are searching for and describing the variables which belong in the human equations. I admit we have not found them all, and some of those we have found may not really be as important as we currently think they are, but $I$ emphasize that, in spite of such tentativeness, we have some very useful ideas to offer. Students are informed the course will include (a) a report on the state of the search for relevant variables in the human equation, (b) a map of how we arrived at each point along the way, and, most importantly, (c) methods of developing and testing theories to see whether and how theories of human and organizational behavior might work for them.

2. Since we cannot claim to know definitively how to motivate an employee or organize a structure, students are offered the tools to find out for themselves.

In the second session, the steps involved in theory construction are addressed (see Figure 1). After a general introduction to the process, I present students with an observation about human behavior, and walk through the steps of building a theory based on the initial observation. I then present students with another observation, break them into discussion groups and turn them loose. Wandering around the room, I listen in on each group and try to help them through any rough spots they might be encountering in managing the theory building process on their own. Afterwards, the class is pulled back together for a discussion of the types of problems they had, and the difficulties involved in building solid theories.
3. Methods of structuring observations to test theories, and the problems that go along with each method are presented from two distinctly different perspectives in the third session. Quasi-experimental and true experimental data collection and intervention sequences and the threats to internal and external validity encountered by each technique are outlined from the professional researchers perspective (Campbell and Stanley, 1963). It is noted that professional researchers are generally seeking models and theories of human and organizational behavior which are applicable across functional, organizational, industrial and, in some cases, cultural boundaries. Putting aside the peculiar demands of hard researchers, a practitioner's view is taken. The contrast is striking.

Managers are practical. Realistic. How do managers find out what the relationships are among people and events in a firm or department? How can a manager find out if a new policy is working the way it should? Methods of finding answers to such questions are presented, along with a discussion of what might go wrong with the various ways of gathering the needed information. I try to emphasize that the concerns students will have as applications-oriented problem solvers will be much different from those in which hard researchers are tangled. If the theories and models a manager develops are accurate enough to work well in their work situation, it is unimportant that their theories are failures by academic standards. If a manager's theories work where they need to work (within the organization), my other evaluation of that theory's "goodness" (validity) simply doesn't matter.

Figure 1

The Process of Theory Building

(adapted from Lave and March, 1972)

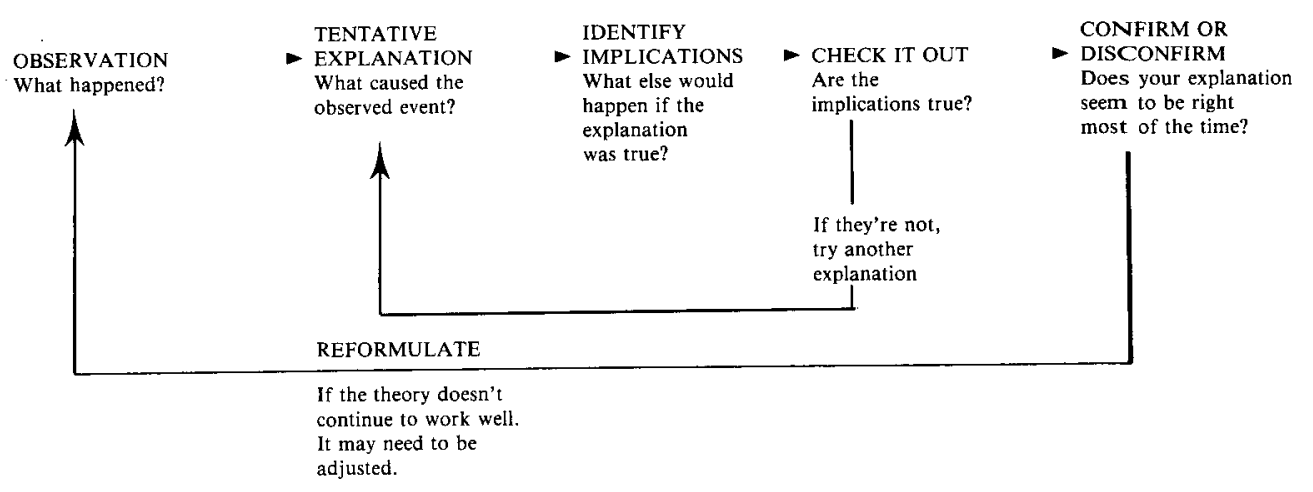


4. Finally, the course proceeds through the usual variety of organizational science theories. After a theory has been presented and discussed in class, students are asked to complete questionnaires designed to measure the theory's availables. For instance, after covering expectancy models of work effort, students are handed an instrument which measures outcome valences, instrumentalities, goal blockage, role perceptions, and perceived equity and the like. The intent is that they see how researchers have operationalized the constructs basic to expectancy models. The process of translating constructs and measures into practical terms then begins. You're a manager. You think expectancy models work. One of your subordinates doesn't seem to be performing the way you think he or she should. What do you do? What questions do you ask your employee? How would you interpret what is said? Which variables do you measure? How do you measure them? What action do you take? What might constrain your actions? How would you manage the constraints? How do you know you were right?

\section{Bridging the Gap: Aftermath}

Bridging the cavernous gap between the abstract world of academic research and putting results to practical use is no simple task, but the payoffs for even a trial crossing can be great. Students come away from their organizational science courses with a kit of tools from which they can draw as their careers call the need. They know how to go about putting a theory to work for them. The fields comprising the organizational sciences avoid inflicting the wounds of their own self destruction. We avert credibility loss by avoiding claims of certainty and determinism by admitting to having only probabilistic solutions. False claims of determinism have done us considerable harm. We may not have precise, panacetic answers, but we do have some excellent questions to ask, and theories worth giving a chance. Maybe it's time we dispelled the false illusions and honestly shared our wealth with students and colleagues.

\section{References}

Campbell, D. T., and Stanley, J. C., Experimental and QuasiExperimental Designs for Research. Chicago: Rand McNally, 1963.

Connolly, T., "On the Relationship between Teaching and Research in Organizational Science." Exchange, The Organizational Behavior Teaching Journal, 5(3), 1980.

Connolly, T., "Uncertainty, Action and Competence: Some Alternatives to Omniscience in Complex Problem-Solving." In S. Fiddle (ed.), Uncertainty: Social and Behavioral Dimensions, New York: Praeger, 1980.

Dodge, L. D., and Ramsey, V. J., "Mock Research as an Instructional Tool." Symposium at the Organizational Behavior Teaching Conference, Los Angeles, June 1980.

Kolasa, B. J., Introduction to Behavioral Science for Business. New York: Wiley, 1969.

Lave, C. A., and March, J. G., An Introduction to Models in the Social Sciences. New York: Harper and Row, 1972.

Mintzberg, H. L., The Nature of Managerial Work. Englewood Cliffs, New Jersey: Prentice-Hall, 1973.

Pinder, C. C., "Concerning the Application of Human Motivation Theories in Organizational Settings." Academy of Management Review, July 1977.

Tosi, H. L., "The Need for Theoretical Development in Organizational Behavior." Exchange, The Organizational Behavior Teaching Journal, 4(3), 1979, 5-7. 